\title{
Criatividade, inovação e economia da cultura: abordagens multidisciplinares e ferramentas analíticas
}

\section{Rosana Icassatti Corazza*}

Faculdades de Campinas (Facamp)

\section{RESUMO}

O limiar do milênio foi pródigo no elogio da criatividade como chave para um novo modelo de desenvolvimento econômico, social e cultural. A produção intelectual vinculada às áreas emergentes da economia da cultura e economia criativa medrou com vigor nas décadas de 1990 e de 2000, tanto no campo acadêmico quanto no político-institucional, identificando a criatividade como recurso crítico para a construção de uma sociedade pós-industrial. Este artigo-resenha examina contribuições cruciais a esse debate, identificando sua procedência institucional, deslindando seu histórico e suas propostas e levantando, a partir das obras resenhadas, pontos relevantes para a compreensão dos rumos do pensamento contemporâneo em Economia sobre as relações entre criatividade, inovação e cultura.

Palavras-CHAVE | Criatividade; Inovação; Cultura; Desenvolvimento.

Códigos JEL | O30; O29; Z10.

\footnotetext{
* A autora agradece aos pesquisadores do Projeto "Perspectivas da Economia da Cultura: um modelo de análise para o caso brasileiro", pelas discussões e comentários: Rodrigo Sabbatini, José Augusto Ruas, Beatriz Bertasso, Daniela Vaz, Sílvio Rosa, Denilson Cordeiro, Leandro Valiati e Stefano Florissi. Reconhecimentos aos apoios do Ministério da Cultura e da Fapesp. Eventuais erros e omissões, como de praxe, são de exclusiva responsabilidade da autora.
} 


\section{Creativity, Innovation and Cultural Economics: multidisciplinary approaches and analytical tools}

\section{ABSTRACT}

The threshold of the Millennium had been prodigal in praise of creativity as the key to a new model of economic, social and cultural development. The intellectual production in the emerging areas of Cultural Economics and Creative Economics thrived vigorously in the 1990s and 2000s in both the academic and the political-institutional fields, identifying creativity as a critical asset for the construction of a post-industrial society. This paper-review examines key contributions to this debate by identifying their institutional affiliation and unfolding their history, their proposals and pointing, from the reviewed works, relevant issues to the understanding of the paths of contemporary thought in Economics on the links between creativity, innovation and culture.

KeYwords | Creativity; Innovation; Culture; Development.

JEL-CODES: O30; O29; Z10.

\section{Introdução}

O limiar do milênio foi pródigo no elogio da criatividade como chave para um novo modelo de desenvolvimento econômico, social e cultural. A literatura sobre economia da cultura e economia criativa, no período, foi copiosa na identificação da criatividade como recurso final para a construção de uma sociedade pós-industrial, identificando a emergência de uma classe criativa, núcleo humano de uma gama ampla de setores nas chamadas indústrias criativas, no seio de uma economia criativa (FLORIDA, 2002; CAVES, 2000; HOWKINS, 2001). À época, cristalizou-se também a proposta da revitalização, pela criatividade, de espaços urbanos carcomidos pelo avanço (ou recuo) do capitalismo industrial - incluindo-se casos de desindustrialização dos quais 
as cidades de Sheffield, Bradford, Manchester, Glasgow e Liverpool são emblemáticos (LANDRY, 2000). Evadiu-se dali a tradicional atividade industrial, levando consigo não apenas os empregos e a renda, mas pouco a pouco o ethos industrial.

Algumas décadas de expansão da empresa-rede de Chesnais, de avanço em escala global da internacionalização produtiva, da intensificação da terceirização da manufatura, com a consequente redução do emprego industrial associada à expansão dos serviços, parecem ter insuflado de entusiasmo alguns espíritos - estaríamos nas fronteiras de um mundo pós-industrial. O setor de serviços, em tese com melhores remunerações, floresceria. O emprego tenderia a ser mais qualificado e os novos postos de trabalho exigiriam, além da alta qualificação, flexibilidade para execução de diferentes tarefas. Nesse cenário, a construção ou manutenção da competitividade dependeria do dinamismo das competências, de trabalhadores e das organizacões.

A precariedade de grande parte dos "novos empregos" nos serviços demorou a ser reconhecida. Perceber os custos da nova divisão internacional do trabalho em matéria de desemprego e de taxas aviltadas de crescimento foi coisa que precisou esperar a crise de 2008 e seus desdobramentos.

Diante desse cenário, interpretações elaboradas no âmbito da economia da cultura e da economia criativa disseminam grande entusiasmo com respeito às possíveis contribuições da criatividade para o desenvolvimento e a competitividade. Como em qualquer campo de investigação incipiente, em que sejam incontornavelmente persistentes divergências as mais fundamentais sobre conceitos, sobre a escolha de indicadores e métricas e sobre a compreensão de nexos causais, o franco entusiasmo que dá a tônica da maior parte dos estudos leva o leitor a certos cuidados.

Neste artigo-resenha, são examinadas contribuições cruciais para esse debate, identificando suas procedências institucionais, recuperando seus históricos e suas propostas e levantando, a partir das obras resenhadas, pontos relevantes para a compreensão dos rumos do pensamento contemporâneo em Economia sobre as relações entre criatividade, inovação e cultura.

\section{Policies para a criatividade}

A primeira tentativa de focalizar o crescimento das indústrias culturais no âmbito das políticas públicas teve lugar há 30 anos, com a iniciativa tomada pela Unesco para direcionar esforços no sentido de compreender as desigualdades em termos de "recursos culturais" entre Norte e Sul, que reconhece contribuições econômicas da cultura e propõe métodos de análise (GIRARD, 1982). 
Na Inglaterra, nas décadas de 1990 e de 2000, sob as gestões de Tony Blair e de Gordon Brown, diversas iniciativas de estímulo às “indústrias criativas” foram qualificadas como "uma rendição das artes e da criatividade aos valores neoliberais", embora suas origens remontem a ações tomadas pelos governos locais de esquerda das antigas cidades industriais - como Liverpool, Manchester, Glasgow, Sheffield e Bradford - 15 anos antes da eleição de Blair (FLEW, 2012, p. 15).

De fato, nos cenários nacionais, Garnham (2005) identifica as políticas culturais do Greater London Council, em meados dos anos 1980, como um momento inicial, embora considere que a ascensão conservadora em 1986 tenha bloqueado a implantação dessas políticas. $\mathrm{O}$ autor também identifica a gênese da noção de "políticas culturais-industriais" na iniciativa de governos trabalhistas das antigas cidades industriais da Inglaterra já em meados da década de 1980. Garnham considera emblemático o caso do trabalho realizado pelo Departamento de Emprego e Desenvolvimento Econômico de Sheffield (DEED, a sigla em inglês), que tentava enfrentar o problema da desindustrialização e do desemprego na cidade. Embora seja considerado paliativo por Hesmonghalgh e Pratt (2005), o programa do DEED procurava reduzir a dependência dos cidadãos de Sheffield do auxílio desemprego e promover uma recuperação econômica com base em projetos culturais.

Volkerling (2001) afirma que, a partir dos anos 1990, tornou-se progressivamente poderosa a ideia de que as indústrias culturais - que passam a ser chamadas de indústrias criativas, entre outras razões para distingui-las do discurso crítico da Escola de Frankfurt e também pela noção de que a exploração econômica dos recursos criativos passa, necessariamente, pela devida apropriação legal de seus benefícios seriam uma via estratégica para revigorar economias nacionais pós-industriais. Neste sentido, a Inglaterra não estava sozinha: os governos da Austrália, do Canadá e da Nova Zelândia também se empenharam, ao longo dos anos 1990, em políticas voltadas às indústrias criativas.

Formalmente, o conceito de indústrias criativas tem sua origem em 1997, na decisão do governo recém-eleito do New Labour, com Tony Blair como primeiroministro, de instituir a Creative Industries Task Force (CITF) como atividade central de seu novo Departamento da Cultura, Mídia e Esportes (DCMS na sigla em inglês para Department of Culture, Media and Sport). A CITF ficou responsável por empreender um mapeamento dos setores ou segmentos criativos, com vistas a propiciar um quadro inicial para mensuração e acompanhamento de suas dimensões econômicas. Os documentos da CITF (DCMS, 1998, 2001) propõem as seguintes 
atividades como "setores da indústria criativa": publicidade; arquitetura; artes e antiguidades; artesanato; design; design de moda; filme; software para lazer interativo; música; televisão e rádio; artes performáticas; mercado editorial; e software.

Cunningham (2004) reporta críticas interpostas a esta classificação, considerada um tanto arbitrária, principalmente por não abranger o setor de patrimônio histórico, a despeito de suas contribuições econômicas, culturais e criativas tão ou mais robustas que alguns dos setores incluídos. O autor salienta, a respeito deste repertório, entretanto, a valoração dos resultados ou dos potenciais comerciais e sua importância estratégica para o perfil de exportações e de "international branding" da Inglaterra.

De toda forma, vê-se nesses esforços ingleses uma tentativa de reposicionamento estratégico da Inglaterra diante de uma nova divisão internacional do trabalho, num cenário de franca emigração (e de expressivo aviltamento) da manufatura. Garnham (2005) destaca que existiu desde logo na Inglaterra a forte tendência ao destaque da importância da exploração de direitos de propriedade sobre aspectos intangíveis do conhecimento num contexto intelectual marcado fortemente pelo discurso da sociedade do conhecimento e do pós-fordismo. Parece aqui de interesse recuperar algumas das ideias do autor a respeito do substrato intelectual sobre o qual emergem, a partir de meados da década de 1980, iniciativas desregulamentadoras que foram chamadas de neoliberais e que vieram a marcar de forma tão indelével o governo Thatcher e que têm persistido na Inglaterra (e não apenas ali) desde então.

Sumariando e parafraseando Garnham (2005:23-24), é possível dizer que aquele período foi influenciado por obras como a de Amin (1994), Post-Fordism, que chamava a atenção para a crescente participação das necessidades imateriais no cômputo geral dos dispêndios com consumo, salientando que a satisfação dessas necessidades não se resumia ao consumo de serviços intangiveis. Certos atributos intangiveis de bens materiais contribuiriam para a satisfação de necessidades como a construção da identidade, o sentido de pertencimento, a aspiração a status. Carros, roupas, joias, acessórios, tanto quanto viagens, restaurantes e outros "consumos de experiência”, ocupam espaço na construção de um estilo de vida associado a uma nova fase da civilização. Aí, o design, a publicidade e o marketing adquirem importância crescente na construção de posições competitivas e na agregação de valor a produtos e serviços. Fala-se em customização, em "descomoditização". O autor argumenta que, no Reino Unido, naqueles anos, o efeito deste discurso foi a aceitação ampla da ideia de que a desindustrialização era uma coisa "boa e libertária", abrindo espaços para que o setor cultural substituísse a manufatura em declínio. Serviu ainda para, 
de um lado, legitimar a desregulamentação das instituições culturais e midiáticas e, de outro, para deslegitimar quaisquer críticas às práticas da publicidade.

Reconhecer o histórico e o contexto intelectual e político do qual emergem, de um lado, as políticas de estímulo à economia criativa e, de outro, como nos interessa especialmente neste artigo-resenha, as contribuições recentes nos campos acadêmicos da economia criativa e da economia da cultura, é essencial. Neste contexto é derivada toda uma gama de açôes de política: as iniciativas de mensuração das indústrias envolvidas e o argumento associado de que elas representam os setores de maior crescimento; a ênfase dada ao treinamento dos trabalhadores criativos; e a importância atribuída à proteção da propriedade intelectual (GARNHAM, 2005).

É preciso, entretanto, ponderar que o modelo britânico não é o único, embora sua experiência muitas vezes se tenha apresentado como paradigmática. Hesmondhalgh e Pratt (2005) avaliam que Canadá, Austrália e Nova Zelândia desenvolveram abordagens mais coerentes pelo fato de, ao lado de reconhecerem o valor econômico das indústrias culturais, atribuírem grande importância, em suas respectivas políticas culturais, ao reconhecimento, à construção e à defesa da cultura nacional. Nesses países, há uma hierarquia nas políticas culturais em termos da valorização, prima facie, dos direitos aborígenes e da "alta cultura", deixando como que num segundo plano as "novas formas culturais", associadas à emergência e à difusão das novas tecnologias. Os autores salientam que esses países se esforçam em resistir à "americanização" que se processa pelas forças mercantis, procurando criar espaços para suas próprias produções e consumos culturais.

Além do objetivo estratégico do desenho de uma nova perspectiva de desenvolvimento econômico, de busca pela competitividade em um cenário de desindustrialização e de estímulo e preservação da cultura nacional, essas políticas também têm destacado seu papel em possibilitar aos cidadãos o mais amplo acesso possível aos bens culturais de qualidade.

Reside aí um dos pontos contraditórios ou dos dilemas apontados por diversos autores que se têm dedicado ao estudo dessas políticas e, novamente, recorremos a Garnham (2005, 2005, p. 28) para expressar esse ponto:

No entanto, o problema aqui é que a qualidade e excelência estão abertas para o teste de mercado das preferências do consumidor e o acesso não é, por definição, um problema, uma vez que uma indústria criativa bem sucedida tenha resolvido o problema de acesso por meio do mercado. Se for bem sucedida, por que precisa 
de apoio público? Se não for, por que o mereceria? A mudança de nomenclatura de induistrias "culturais" para "criativas" serve como disfarce para essas contradiçôes e dilemas de política. As demandas por recursos públicos são justificadas não em termos de politicas para as artes [e cultura], mas em termos de politicas para a sociedade da informação. O suposto resultado não é a ampliação do acesso nem a qualidade [...] mas os empregos e os ganhos de exportação em uma economia competitiva global.

As questões são de grande relevância, pois "indústrias criativas" e toda a terminologia correlata que, como veremos, abrange classes criativas, indústrias criativas e assim por diante são categorias que, embora bastante recentes nos discursos acadêmicos, têm experimentado grande influência no Brasil, tanto na esfera da política quanto na dos negócios. Supõe-se, como observa Cunningham (2004), que essa terminologia capture de forma importante a dinâmica da "nova economia" ou da "era do conhecimento".

\section{Abordagens conceituais sobre criatividade no debate contemporâneo}

Uma revisão dos tratamentos acadêmicos a respeito da criatividade que vêm dando suporte às discussões contemporâneas permite o reconhecimento de pelo menos quatro obras fundamentais que portam elementos conceituais e aplicados sobre os seguintes temas: indústrias criativas (CAVES, 2000); cidades criativas (LANDRY, 2000); economia criativa (HOWKINS, 2001); e classe criativa (FLORIDA, 2002).

Nos itens a seguir, são apresentados elementos que devem permitir ao leitor uma introdução a essas contribuiçôes, cujo domínio é crítico para a compreensão do debate em foco.

\subsection{Indústrias criativas segundo Richard Caves: um problema de contratos}

Richard Caves, economista e professor da Universidade de Harvard, é reconhecido por suas contribuições na área de organização industrial, tanto em aspectos teóricos quanto aplicados nas temáticas atinentes especialmente à teoria dos contratos. Seu livro Creative industries: contracts between arts and commerce, de 2000, explora aspectos organizacionais das indústrias criativas, nas quais são incluídas as artes visuais e performáticas, cinema, teatro, áudio e mercado editorial. 
Partindo da ideia de que, em cada um desses segmentos das indústrias culturais, os insumos artísticos são combinados com outros, "comuns" (bumdrum inputs), a proposta de Caves (2000) é investigar e explicar a lógica dos arranjos estruturais dessas indústrias, com foco especial nos contratos entre os agentes criativos e os "demais agentes da indústria".

Caves explica que a organização das empresas voltadas à elaboração e comercialização de produtos ou bens criativos se dá segundo diversas estruturas. Algumas empregam diretamente o pessoal criativo utilizando contratos de longo prazo, enquanto outras estabelecem relações externas com esse pessoal, usando contratos diversos. Nesses casos, agentes ou empresários podem atuar como administradores de carreiras artísticas, como procuradores ou intermediários, negociando os contratos e procurando compatibilizar os talentos criativos com os interesses dos empreendedores.

No que tange à escala, as empresas nas indústrias criativas podem ser tanto pequenas, normalmente concentrando seu métier na seleção e no desenvolvimento de novos talentos criativos, quanto corporações de grande escala, em geral operando as tarefas de promoção, distribuição e comercialização de bens criativos já reconhecidos pelo mercado. Esta estrutura foi descrita originalmente por Stigler como oligopólio em franjas.

Segundo esta estrutura, o núcleo oligopolista seria composto pelas grandes corporações com funções especialmente na área de promoção (inclusive marketing), distribuição e comercialização dos bens criativos estabelecidos, enquanto a franja competitiva dedicar-se-ia às atividades mais arriscadas da criação e desenvolvimento de novos talentos (BENHAMOU, 2007).

Há ainda casos como os das artes performáticas, nos quais a estrutura mais adequada seria conformada por organizaçôes sem fins lucrativos, devido a elevados custos fixos.

Caves $(2000,2003)$ propõe características estruturais que sustentariam a organização das indústrias criativas, além de distinguir o que designa como "núcleo" (artes e entretenimento) das demais indústrias e diferenciar atividades internamente a este núcleo.

Para cada característica, Caves $(2000,2003)$ propõe uma frase-síntese. Nobody knows refere-se à incerteza fundamental com a qual se defronta o produtor de um bem criativo, por exemplo. Esse tipo de bem é concebido como um "bem de experiência", sendo que o produtor deve apresentá-lo aos potenciais consumidores antes de saber seus respectivos preços de reserva. Embora possa contar com a aprendizagem de 
experiências passadas, a incerteza não se dissipa e é praticamente impossível alcançar um valor de antemão, de modo que a frase nobody knows significa a incerteza ubíqua em cada lançamento. Art for the art's sake representa outra propriedade fundamental dos bens criativos e está associada à atitude do artista com relação ao seu trabalho. Enquanto os economistas consideram a "desutilidade" do trabalho, "a arte pela arte" evoca a utilidade especial que o artista usufrui pela realização de seu trabalho. Aqui, é importante salientar que, aceitando-se esta expressão na elaboração de contratos entre a classe criativa e o mundo dos negócios, torna-se possível considerar que o trabalho do artista possa ser menos bem remunerado, pois o artista obtém prazer com sua performance. A expressão também tem a ver com o gosto e a forma específica pela qual o trabalho é representado. Este fato deve ter implicaçôes para a produção do bem criativo, pois podem existir restrições eventualmente impostas pelo artista para sua participação no processo. As preferências do artista quanto a como executar seu trabalho criativo podem complicar o processo de elaboração de contratos.

Outras características apontadas por Caves $(2000,2003)$ ainda envolvem:

- o fato de que os trabalhadores criativos se importam com seus produtos, interessando-se por questões como "para quem são produzidos e como são consumidos" (Caves usa aqui a expressão motley crew);

- o caráter essencialmente diferenciado do produto no sentido "horizontal" (a expressão, neste caso, é infinite variety);

- a diferenciação vertical das qualificações ou das capacitações dos trabalhadores (para a qual a designação é $A$ list/ $B$ list);

- a coordenação temporal da produção - que envolve riscos de coordenação quando da necessidade da colaboração de diversos artistas - e do consumo, em que a seta temporal é essencial (Caves denota esta característica pela expressão time flies);

- a difícil questão da durabilidade dos produtos e das rendas provenientes de sua produção e comercialização (Ars longa é a expressão empregada por Caves como referência a esta característica).

A pesquisa futura sobre indústrias criativas, conforme vista por Caves (2003), deveria ser instrumentalizada pela teoria dos contratos, que permitiria deslindar os padrões de acordo alcançados pelas indústrias criativas para lidar com os intrincados problemas de incentivo. 


\subsection{Cidade criativa: propostas para o enfrentamento da "crise urbana"}

No mesmo ano da publicação de Caves, Charles Landry lançou o livro The creative city: a toolkit for urban innovators. $\mathrm{O}$ autor tem uma trajetória intelectual e profissional interessante. Depois de graduado em Estudos Internacionais, na Paul H. Nitze School of Advanced International Studies em Bologna, pertencente à Johns Hopkins University, concluiu ali também sua pós-graduação em Economia Política. Foi contratado pelo Lord Skidelsky, historiador econômico e autor da talvez mais reconhecida biografia de John Maynard Keynes, para um trabalho de pesquisa sobre os desafios da sociedade pós-industrial. Com vinte e poucos anos, Landry persuadiu-se que os desafios econômicos apenas poderiam ser trabalhados num quadro mais amplo, em seu contexto cultural. O trabalho com Skidelsky lhe rendeu conhecimento e contatos para que sua carreira seguisse outros rumos, nos quadros tecnocratas da União Europeia. Frustrado, entretanto, com os tratamentos dados pela Comissão Econômica Europeia a temas de relação entre economia e cultura, e influenciado pela crença de que a criatividade pode ser a ponte para a transição para novos futuros, Landry fundou, em 1978, uma consultoria em planejamento cultural - a Comedia, que lhe serviu de plataforma para as atividades de redação e consultoria e para o estabelecimento de parcerias pelas próximas três décadas. A maior parte desse tempo, Landry dedicou-se à reflexão e à persuasão, em palestras.

Seu livro The creative city: a tookit for urban innovators tem como anseio apresentar novas formas de se pensar as cidades e de regenerá-las, partindo do reconhecimento de que as cidades se encontram em fase de modificaçôes dramáticas - a crise urbana -, sendo urgente uma mudança paradigmática. Os problemas urbanos contemporâneos não podem, argumenta Landry (2000), ser resolvidos com o velho aparato intelectual.

A crise urbana, de acordo com autor, envolve uma diversidade de fenômenos. A crise se origina e se propaga com o desaparecimento das antigas indústrias, conforme o valor adicionado se deve menos à etapa da manufatura e mais à aplicação de novo conhecimento a produtos, processos e serviços, e que torna menos relevantes fatores que uma vez modelaram o desenvolvimento da cidade, como o sistema de transporte e a proximidade de fontes de matérias-primas. A distribuição pode ser feita de formas diferentes. O transporte é mais um problema de mobilidade de pessoas do que de mercadorias. Outros problemas emergem, em parte, em razão da decadência das antigas formas de vida e de trabalho, que se desenvolviam em torno do escritório e da fábrica. Lidar com o crime, eliminar a insegurança e melhorar a qualidade do 
ambiente tornam-se questôes vitais. Lidar com a informação em tempo real e tirar partido da globalização podem ser questões oportunas e mesmo estratégicas.

Embora a crise urbana seja algo em si negativo, a perspectiva da Cidade Criativa é otimista a respeito das possibilidades que se abrem ao futuro das cidades. Ela prevê muito espaço para comunicação, para novas ideias e para a criação de riquezas. Landry (2000) lança um chamado para o uso da imaginação na vida urbana, oferecendo mais de 60 exemplos para persuadir o leitor de sua própria crença de que é possível superar os obstáculos e aproveitar oportunidades.

O maior recurso que as cidades possuem, em sua visão, é seu povo. Sua criatividade, sua imaginação, suas motivaçóes e seus desejos estariam tomando o lugar anteriormente ocupado pela vantagem da localização, da posse de recursos naturais e do acesso aos mercados para forjar seu desenvolvimento.

Ele reconhece que as cidades, tendo se tornado demasiadamente grandes e complexas, apresentam problemas cada vez mais profundos e abrangentes. Ao lado disso, o autor advoga que a gestão urbana deve e pode lutar para enfrentá-los. Há especificidades regionais. Diante da globalização, na Ásia, o crescimento da manufatura é pujante, enquanto na Europa as velhas indústrias estão desaparecendo e mais capital intelectual é aplicado a processos, produtos e serviços.

Landry (2000) assevera que, acima de tudo, há que se empregarem métodos para se pensar criativamente, planejar criativamente e agir criativamente. Nos exemplos apresentados em seu livro, o autor propõe conceitos próprios para o planejamento urbano - um took kit para o planejador, como sugere o título da obra, que inclui, entre outras, suas noções de "ciclo de vida da inovação urbana" e a "Pesquisa e Desenvolvimento urbanos". Além disso, ele propõe formas de desenvolvimento, implantação e replicação de projetos-piloto, apresenta estratégias de uso de recursos culturais, explica como a cidade pode ser vivida como um organismo que aprende e também fala de "alfabetização urbana": a capacidade de "ler e compreender as cidades".

Enfim, Landry (2000) apresenta propostas para as políticas de planejamento urbano num mundo - ou numa parte dele - em transição para uma era pós-industrial.

\subsection{Economia criativa: criatividade como fonte de riquezas}

Em se tratando do debate atual sobre criatividade e desenvolvimento, o livro de John Howkins, Creative economy: how people make money from ideas, publicado em 2001, é uma referência inescapável. Howkins tem uma carreira longa e bem-sucedida na área de comunicação: televisão, filmes, mídias digitais e mercado editorial constam 
de seu currículo. Foi responsável por emissóes de TV e rádio na Europa pela HBO e pela Time Warner, no período de 1982 a 1996. É vice-presidente do British Screen Advisory Council (BSAC), membro do Comitê Consultivo do Programa de Economia Criativa das Naçoes Unidas para o Desenvolvimento e conselheiro do UK Arts and Humanties Research Council (AHRC). Sua carreira acadêmica é mais tardia, sendo professor visitante na City University (Londres) e na Shangai School of Creativity (China).

A trajetória profissional de Howkins permite compreender o sentido de sua contribuição: de economista a executivo no mundo da mídia, torna-se conselheiro de entidades britânicas e das Naçôes Unidas para os setores que podem ser chamados de culturais e criativos. Cunningham (2004) prefere reconhecê-lo como "analista de negócios”. Nessa trajetória nasceu sua interpretação, que tem origem no conhecimento prático da indústria da mídia e com sua experiência no campo das policies no Reino Unido e no cenário mundial.

Seu livro sobre economia criativa contribui para uma grande dilatação do conceito de indústrias criativas e da proposição da importância dos direitos de propriedade intelectual para o desenvolvimento da economia criativa. Howkins (2001) amplia drasticamente a noção de indústrias criativas, incluindo todos os setores da economia cujos produtos e serviços podem ser protegidos por esquemas legais de propriedade intelectual, como patentes, copyrights, trademarks e design. Como se sabe, cada forma de direito intelectual tem seu próprio corpo legal e instituições reguladoras. E cada uma dessas formas tem origem no desejo de proteger um tipo de produto ou serviço criativo. Na visão de Howkins (2001), cada forma de proteção da propriedade intelectual corresponde a uma indústria criativa. Assim, sua definição de economia criativa inclui a publicidade, a arquitetura, as artes, o artesanato, o desenho industrial e gráfico, a moda, a indústria cinematográfica, a música, as artes performáticas, o mercado editorial, as atividades de Pesquisa e Desenvolvimento (P\&D), software, brinquedos, jogos eletrônicos e video games, a televisão e o rádio (HOWKINS, 2001, p. 88-117).

Considerando a perda da importância relativa da manufatura diante de outras formas de agregação de valor, em especial no cenário econômico britânico no final do século XX, Howkins (2001) argumenta que os produtos/serviços protegidos por alguma forma de direito de propriedade intelectual, como os livros, filmes e a música, aportam mais rendas de exportação do que produtos manufaturados. Fenômenos como as Spice Girls e Harry Potter foram responsáveis, individualmente, pelo aporte de recursos expressivos nas contas externas britânicas no final dos anos 
1990 e durante a década seguinte, respectivamente. Ou seja, é possível interpretar a ideia fundamental de Howkins (2001) como o reconhecimento do fato de que, no cenário de transferência ou migração da manufatura para a periferia, a criatividade protegida por direitos de propriedade intelectual torna-se um grande negócio.

Uma novidade no trabalho de Howkins é, como se depreende, a forma pela qual ele integra setores de fora do domínio das artes, como a ciência, na noção de economia criativa. Tipos diferentes de criatividade, desde que devidamente protegidos, são recursos da economia criativa.

Descobertas científicas, como na genômica, podem ou devem ser patenteadas? Essa questão, tão pertinente e reconhecida quanto controversa nos meios científicos, é central na abordagem de Howkins. Apenas se torna "propriedade" (e, portanto, recurso capaz de gerar riquezas apropriáveis do ponto de vista privado) a criatividade legalmente protegida. Nas palavras de Healy (2002, p. 19): "Creativity by itself will not make anybody rich. Intellectual property laws are what do that."

\subsection{Classe criativa: as ideias de Florida em perspectiva}

O livro de 2002 de Richard Florida, The rise of the creative class, é uma referência nos campos de debates em que se confrontam ideias sobre criatividade para o desenvolvimento. Trata-se de uma referência em pelo menos dois sentidos: para os defensores da necessidade de promoção da chamada classe criativa; e para seus detratores.

Florida é diretor do Martin Prosperity Institute, criado especialmente para ele na Universidade de Toronto, onde também é professor de Negócios e Criatividade, na Rotman School of Management. Sua experiência profissional anterior envolve o ensino superior na George Mason University, na Carnegie Mellon University, tendo sido ainda professor visitante em Harvard no MIT. Seu PhD em Planejamento Urbano é da Universidade de Columbia e na última década foi um palestrante dos mais requisitados, na área da economia criativa. Foi um dos European Ambassador for Creativity and Innovation, 2009, ano declarado pela União Europeia como "Ano Europeu da Criatividade e da Inovação”.

Em seu primeiro livro, sobre a chamada classe criativa, Florida (2002) a define e propõe meios para medi-la e classificá-la, uma vez que esta seria, no julgamento do autor, a característica mais essencial das cidades criativas. Sua abordagem propõe três elementos que, em sua visão, deverão se tornar progressivamente centrais para a classe criativa: a tecnologia, o talento e a tolerância. Os chamados "3 Ts" não tornariam trabalhadores ou cidades criativos. Eles são considerados fatores de 
atração. A classe criativa é definida como aquelas ocupações que vão de artistas e desenvolvedores de softwares (o core supercriativo) aos gestores e especialistas da área jurídica (os "profissionais criativos").

Essas ocupaçôes atuariam como "magnetos" atraindo empresas de rápido crescimento, alta tecnologia e grande mobilidade. Para Florida, as pessoas que ocupam essas posições criativas são tolerantes e os ambientes de trabalho se assemelham mais a espaços boêmios de consumo.

$\mathrm{O}$ autor advoga que os territórios ou cidades precisam atrair tipos particulares de trabalho ou ocupações que, por sua vez, atrairiam empresas de alta tecnologia. Um centro boêmio - com bares, casas noturnas e assemelhados - seria o atrativo para estimular a presença de uma força de trabalho cujo estilo de vida tende a valorizar o consumo dessas experiências. Por sua vez, a presença de tal força de trabalho seria uma incitação à instalação das empresas de alta tecnologia, levando ao crescimento do território - ou cidade - em questão.

Florida (2002, p. 3) acredita que certos jovens, por suas:

[...] inclinaçôes em termos de estilo de vida representam uma força profundamente nova na economia e na vida da America. [...] [são membros] do que eu chamo a classe criativa: um segmento da força de trabalho que cresce rapidamente, altamente educado e bem pago, de cujos esforços o lucro das corporaçôes e o crescimento econômico dependem cada vez mais. Membros da classe criativa realizam uma ampla variedade de trabalho em uma ampla variedade de indústrias - da tecnologia ao entretenimento, do jornalismo às finanças, da manufatura às artes. Eles não pensam conscientemente sobre si mesmos como uma classe. Ainda assim, eles partilham um ethos comum que valoriza a criatividade, a individualidade, a diferença e o mérito.

A lógica defendida por Florida, conforme comenta Pratt (2008), tem a ver não apenas com a percepção sobre os efeitos multiplicadores de consumo, mas trata-se de uma hipótese forte a respeito das relaçôes e da causalidade entre a vida boêmia, a presença da classe criativa e o crescimento econômico. De acordo com Pratt (2008), muito do tratamento desenvolvido por Florida e a própria origem de seu argumento, recuperado brevemente acima, têm a ver com abordagens sobre a teoria da mobilidade do capital humano e, a partir de suas próprias observaçóes a respeito do estilo de vida valorizado pelos jovens da classe criativa, o autor elabora o argumento sobre como atraí-los e, assim, atrair as empresas de alta tecnologia. 
Algumas das críticas à interpretação de Florida sobre a "classe criativa" incluem: ela se restringe aos trabalhadores que receberam educação superior, estejam eles ou não exercendo algum trabalho criativo, sendo excluídos todos os trabalhadores criativos sem diploma universitário (MARKUSEN et al., 2008, p. 27); os elos causais entre as variáveis escolhidas por Florida são discutíveis, sofrendo de uma inescapável circularidade (PECK, 2005); a competição por investimentos entre as cidades é um jogo de soma zero (PRATT, 2008); e a criatividade é tratada por Florida (2002, 2005) como um atributo do trabalhador, ou seja, do indivíduo, como se este pudesse ser isolado de conexões com a indústria, com a produção e mesmo com relação ao consumo (PRATT; JEFFCUTT, 2009).

\subsection{Cultura, criatividade e inovação: foco na indústria ou no artista?}

Tendo em vista as contribuições abordadas anteriormente, destacam-se algumas observaçōes relevantes para a compreensão de aspectos centrais no debate atual sobre criatividade, inovação e cultura. Muitas questôes poderiam ser destacadas a partir das obras indicadas: o sentido de criatividade; a compreensão da "classe criativa"; ou as perspectivas de suas contribuições para o desenvolvimento. Optou-se aqui pelo caso específico da abrangência do conceito de "indústria criativa". A Figura 1 permite uma compreensão comparada das contribuições dos autores examinados.

FIGURA 1

Atividades/setores compreendidos pelas indústrias criativas

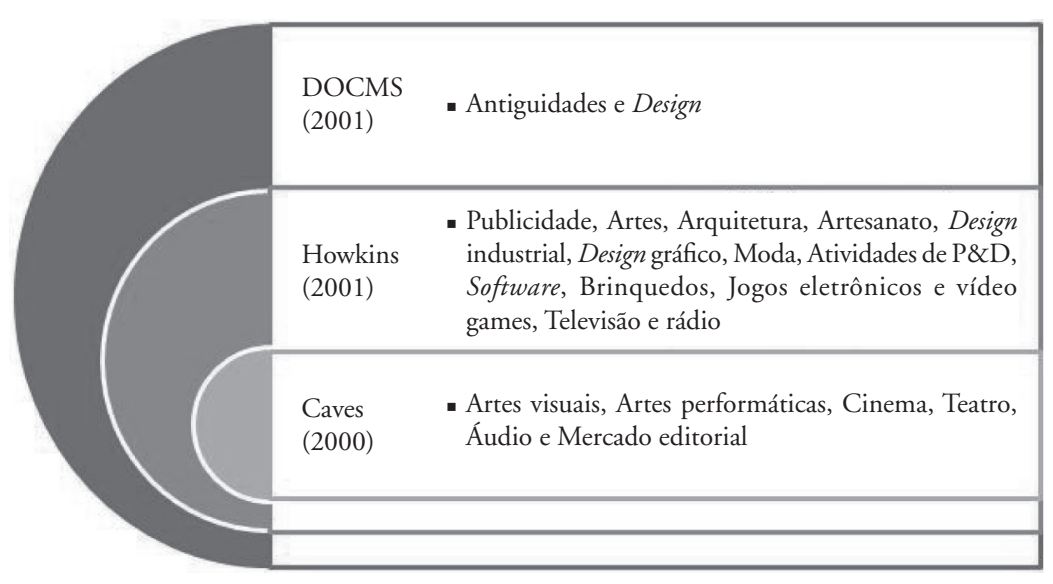

Fonte: Elaboração da autora. 
Conforme é possível observar pela figura, a abrangência do conceito de indústrias criativas varia fortemente segundo o enfoque privilegiado pelos autores, sendo seu escopo mais restrito na abordagem de Caves $(2000,2003)$ e extremamente ampliado nas de Howkins (2001) e da DCMS (2001). Embora tendo estendido seus escopos, essas abordagens excluem áreas tradicionalmente vinculadas às artes e à cultura, como museus, galerias de arte e o patrimônio histórico-cultural de maneira geral, a despeito de suas respectivas contribuições como atraçōes turísticas e para o prestígio cultural de que a Inglaterra goza no cenário internacional.

Recentemente, Flew (2012) investigou e interpretou os distintos posicionamentos institucionais na esfera de policy na Inglaterra comparando, por exemplo, posiçōes como a da NESTA (National Endowment for Science, Technology and the Arts, a Fundação britânica para inovação) e a da The Work Foundation (TWF - Fundação vinculada à Universidade de Lancaster, comprometida com a promoção do emprego de qualidade).

Não cabe aqui detalhar esta análise, dados o escopo e a extensão deste artigo-resenha. Entretanto, é possível observar, conforme apontado por Flew (2012), que persistem duas visões distintas sobre as indústrias criativas: de um lado, aquela que privilegia o "núcleo criativo" (no caso a TWF e o DMCS); de outro, aquela que privilegia os nexos industriais (a NESTA). Os enfoques comungam, apesar dessa distinção, de uma confiança na indústria criativa como um portal para uma nova era de desenvolvimento, ou, ao menos, como um veio de oportunidades para o reposicionamento de países desindustrializados em uma nova divisão internacional do trabalho.

\section{Olhares multidisciplinares sobre os setores criativos}

As fórmulas de desenvolvimento baseadas no apoio aos setores ditos criativos se difundem de forma mais veloz e vigorosa do que organizada. Nesse cenário, a obra organizada por Pratt e Jeffcutt (2009) torna-se um alento. Diante do entusiasmo da literatura sobre o tema, os autores alertam que criatividade e inovação frequentemente são apresentadas como "magic bullets: one shot sollutions to problems". O título do primeiro capítulo é bem provocativo: "Creativity, innovation and the cultural economy: snake oil for the twenty-first century?"

Leitores habituados à abordagem frankfurtiana da "indústria cultural” poderiam entrever nas recentes defesas das indústrias criativas algo como uma incorporação

1 Conta-se que os imigrantes chineses que trabalharam na construção da Ferrovia Transcontinental nos EUA, em meados do século XIX, usavam óleo de cobra contra as dores nas articulações. A prescrição era combatida pelos tenentes da medicina ocidental e, desde então, snake oil tornou-se expressão popular para designar charlatanice e falsas curas (GRABER, 2007). 
dialética da promoção dos setores de entretenimento, da moda, da publicidade, etc., num arcabouço de políticas públicas culturais e industriais. É possível. Mas não é com isso que nos deparamos na obra organizada por Pratt e Jeffcutt. Para conhecer essas contribuições, esta seção está organizada em duas partes, sendo a primeira dedicada à apresentação dos autores e dos capítulos, enquanto a segunda sintetiza os temas identificados por Pratt e Jeffcutt (2009) como unificadores dessas contribuições.

\subsection{Abordagens multidisciplinares em criatividade, inovação e cultura}

Os autores dos capítulos organizados por Pratt e Jeffcutt provêm de diversas searas epistemológicas. Embora isso nos devore um longo parágrafo, conheçamos brevemente a procedência dos autores. Crhis Bilton é diretor de pós-graduação do Centro de Estudos para Políticas Culturais da Universidade de Warwick. Doris Eikhof é lecturer em Estudos Organizacionais na Universidade de Stirling. Simon Frith é professor de música na Universidade de Edinburgh. Martin Cloonan é senior lecturer em música na Universidade de Glasgow. John Williamson é doutorando na Queen Margaret University - além de empresário da banda indie escocesa Belle and Sebastian. Rosalind Gill é professora de psicologia social e teoria cultural na Open University. Galina Gornostaeva é pesquisadora no Departamento de Geografia da London School of Economics (LSE). David Hesmondhalgh é professor de Indústrias de Mídia e Música na Universidade de Leeds. Tom Hutton é professor no Centro de Assentamentos Humanos na Universidade de British Columbia. Deborah Leslie é professora associada do Departamento de Geografia na Universidade de Toronto. Mark Lorenzen é professor associado do Departamento de Inovação e Economia Organizacional na Copenhagen Business School - além de membro do comitê executivo da DRUID - Danish Research Unit on Industrial Dynamics e editor executivo do periódico Industry and Innovation. Sean Nixon é professor de mídia e de estudos culturais no Departamento de Sociologia da Universidade de Essex. Dominic Power é professor de Geografia Econômica na Universidade de Uppsala. Norma Rantisi é professora associada do Departamento de Geografia, Planejamento e Meio Ambiente da Universidade de Concordia em Montreal. E Sara Selwood é professora de Gestão e Política Cultural na City University.

Os perfis de Andy Pratt e Paul Jeffcutt, bem como suas procedências acadêmicas, não são menos diversificados. Andy Pratt, geógrafo, é diretor do Urban Research Center da LSE e tem trabalhado por mais de uma década, na forma de pesquisas e publicaçôes, com economia da cultura e economia criativa. Recentemente, atua 
como consultor da Unctad e da Unesco nesses assuntos. Paul Jeffcutt é um poeta com várias obras publicadas e premiadas, além de economista pela LSE e diretorfundador do Centre for Creative Economy da Queen's University, onde também é professor de gestão do conhecimento.

O livro organizado por Pratt e Jeffcutt foi publicado pela Routlege, na série preparada pelos professores John Cantweel, professor honorário da SPRU - Science Policy Research Unit, da Universidade de Sussex (UK) e David Mowery, da Haas School of Business (Berkeley, USA): Routledge Studies in Global Competition.

A proposta desta obra - fruto de quatro anos de investigaçóes financiadas pelo ESRC e pelo AHRC em economia cultural - é lançar sobre o objeto um olhar multidisciplinar, compondo, assim, visões da sociologia, da economia, da geografia, dos estudos culturais e de gestão.

Pratt e Jeffcutt pretendem construir uma interpretação que constitua uma abordagem melhor do que aquela oferecida pelos estudos correntes que, segundo eles, se fundamentam no seguinte conjunto de questôes: Qual é a relação entre criatividade e inovação? A inovação e a criatividade encontrada na economia da cultura são as mesmas ou são distintas da inovação e da criatividade encontrada "no resto" da economia? Qual a relação entre a economia da cultura e "o resto da economia"?

$\mathrm{Na}$ busca pelas "perguntas corretas" a guiar seus esforços intepretativos, os autores examinam algumas falácias de autores bem conhecidos da literatura sobre criatividade. É reconfortante, por exemplo, encontrá-los a discutir criticamente as contribuições do hoje já não tão acreditado Florida, sobre sua creative class. Esta seria constituída, como já mencionado, por jovens profissionais em áreas intensivas em conhecimento, como as tecnologias "de ponta", o marketing, o design, a moda e as finanças, com formação superior e, sobretudo, apreciadores de um estilo de vida boêmio e hedonista. A tese de Florida, já apresentada neste artigo-resenha e aqui retomada rudemente, é a seguinte: a classe criativa busca cidades tolerantes e culturalmente ricas; atrair estes profissionais impõe às cidades a criação de um cultural magnet (o downtown boho); as indústrias criativas, advoga Florida, seriam atraídas pela presença desses profissionais. Não cabe aqui alongar as críticas dos autores ao snake oil de Florida, mas convém salientar, em respeito aos bons estudos sobre localização industrial, arranjos produtivos locais e sistemas de inovação, um ponto central do argumento: o caráter relacional e contextual do conhecimento.

Parte da coerência interna do livro provém de um conjunto de questões unificadoras sobre as indústrias culturais e criativas. Enquanto o campo da economia criativa é marcado pela ideia de que essas são indústrias diferentes "do resto da 
economia" e gozam de particularidades razoavelmente homogêneas, como se procurou sublinhar na seção anterior, os autores defendem que são relevantes as variações entre as diferentes indústrias e mesmo dentro da mesma indústria ao longo de suas cadeias de valor. Uma questão relevante é saber se as diferentes indústrias criativas são espécies do mesmo gênero e em que medida e por que elas diferem entre si.

As dificuldades que se colocam são tanto de natureza conceitual quanto empírica. Contribuições caras à Economia da Inovação e à Sociologia da Tecnologia são retomadas a fim de esclarecer pontos como: "Inovação e criatividade são qualidades de um indivíduo ou sistema?" "Como considerar os efeitos de aprendizagem e feedbacks complexos entre indivíduos e sistemas?” Como os estudos empíricos parecem crescentemente demonstrar, também é preciso considerar o colapso das categorias produção e consumo na explicação do processo criativo.

Para por em prática esta investigação, os autores conceberam uma abordagem para testar suas questóes de pesquisa. Parte substancial desta abordagem consiste em examinar a organização (interna e externa) de indústrias culturais e criativas e seus processos laborais, pontos que geralmente permanecem como suposições sobre certa homogeneidade entre as diferentes indústrias.

As indústrias cobertas pela estrutura do livro compreendem: publicidade; música; filme e TV; novas mídias; design; e "museus, artes visuais e performáticas". Dois capítulos são dedicados ao estudo de cada indústria. Por vezes, cada capítulo enfoca a indústria de uma perspectiva metodológica particular. Por vezes, ilustra particularidades de uma indústria. Esta lógica de estruturação do livro guarda similaridade com o ambiente de debate acadêmico que está na origem da obra: uma série de seminários objetivando aquilatar o estado das artes e discutir perspectivas analíticas sobre as indústrias culturais e criativas.

Os dois primeiros capítulos, de Bilton e Nixon, sobre publicidade, exploram a natureza do trabalho (comercial e criativo/artístico) e as estruturas e a operação de agências no caso londrino, examinando as qualificaçôes dos trabalhadores, suas formas de recrutamento e suas respectivas culturas organizacionais.

Os dois capítulos seguintes são dedicados à música. Hesmondhalgh se debruça sobre a questão do copyright. O autor é particulamente habilidoso ao tratar a questão de como a norma frequentemente apresentada como proteção ao artista pode, não raro, ser instrumento eficaz de transferência de direitos para uma grande corporação. Frith, Cloonan e Williamson, por sua vez, abordam a indústria da música na Escócia, discutindo o uso da música como instrumento de desenvolvimento econômico que, por sua vez, falha em atender ao desenvolvimento desta própria indústria. 
O terceiro par de capítulos cobre a produção de filmes, incluindo o caso da televisão. O capítulo de Lorenzen contextualiza a atividade criativa na produção de filmes em termos do desenvolvimento histórico desta indústria, focalizando os determinantes de seu conteúdo, a organização da cadeia (integração horizontal), seus custos, os copyrights e outras formas de direitos. As questões de investigação sobre a indústria cinematográfica fazem deste capítulo leitura obrigatória para a condução de estudos sobre clusters cinematográficos em diversas partes do mundo. O capítulo de Pratt e Gornostaeva sobre governança da inovação em cinema e televisão investiga o caso londrino. Com o diagnóstico de que esta indústria se encontra no front do avanço de novas tecnologias de digitalização, os autores propõem que a ela se aplica a ideia de inovação e criatividade como mudanças sistêmicas interconectadas em redes de empresas, afetando a configuração e a reconfiguração desta indústria e exigindo uma massa crítica em termos da base laboral - cuja criação e sustentação são grandes desafios.

Dedicado às novas mídias, o quarto par de capítulos focaliza particularmente o web design. Vancouver é o caso apresentado por Hutton para evidenciar a forma pela qual esta indústria está incrustada no contexto urbano e físico da cidade. Originalmente sustentada pela economia florestal e portuária, Vancouver hoje é reconhecida por suas atividades em setores ditos criativos. O desenvolvimento do cluster de novas mídias é descrito por Hutton como contingencial, caracterizado pela sinergia entre as atividades de pesquisa e de formação e qualificação de trabalho nas universidades e institutos de pesquisa locais. Recentemente, a atividade do Departamento de Planejamento da Cidade tem sido importante na condução de sua "vocação". Gill salienta que as "novas" práticas de trabalho em web design correspondem a formas particulares de expressão de identidade e de sociabilidade, aliando valores "artísticos" e "comerciais".

No quinto par de capítulos, que examinam a indústria do design, Leslie e Rantisi investigam a promoção do design em Montreal, enquanto Power ilustra o mesmo tema para o caso de Estocolmo. Nesses casos, os autores procuram explicar os efeitos sinérgicos dos arranjos locais.

O "núcleo criativo" das indústrias culturais - museus, artes visuais e performáticas - é abordado no última par de capítulos. Este núcleo constitui o epicentro do debate seminal nos estudos em economia da cultura. Os malabarismos para o financiamento dessas atividades e a divisão de papéis entre o poder público e a iniciativa privada já foram tratados originalmente por Baumol e Bowen (1966). Curiosamente, as autoras não aludiram aos achados dos ilustres mestres.

Em suma, a visão proposta pelos autores sobre "criatividade, inovação e economia cultural" consiste numa coletânea de estudos sobre a indústria da publicidade, da música, do filme e da TV, das novas mídias, do design e de "museus, artes visuais e 
performáticas". São estudos conceituais e de caso, multidisciplinares, bem amarrados pela discussão conceitual e metodológica conduzida por um conjunto de questôes substanciais sobre organização e trabalho, passando pelas inescapáveis considerações sobre governança e apropriabilidade.

\subsection{Criatividade, inovação e cultura: uma síntese de temas cruciais}

A tarefa de lograr uma coerência acima dos olhares disciplinares cabe aos organizadores, num esforço analítico e ensaístico nos capítulos de introdução e de conclusão, culminando na identificação de seis temas considerados da maior relevância. Os parágrafos a seguir compilam e sintetizam esses temas.

O primeiro tema está relacionado à questão dos clusters. Pratt e Jeffcutt (2009) sustentam que há evidência de que os arranjos locais são relevantes no caso das indústrias criativas em termos da partilha do conhecimento, mas que os aspectos relacionados à provisão de infraestrutura têm sido o foco privilegiado da ação de planejadores e policy makers, que os entendem como espaços de co-consumo (coconsumption spaces ou honey pots) ou geradores de economias de aglomeração. A perspectiva da provisão de infraestrutura é desacreditada pelos autores com base na avaliação de que as indústrias criativas/culturais têm se mostrado muito seletivas em suas preferências locacionais: os milieux históricos e culturais importam e a path dependence observada nos investimentos parece desencorajar "those seeking to jump to the 'cultural bandwagon"” (PRATT; JEFFCUTT, 2009, p. 272).

$\mathrm{O}$ segundo tema tem a ver com a autoimagem ou a identidade de algumas das indústrias criativas e de seus trabalhadores. Este tema é de grande interesse quando se trata de se pensar a "classe criativa". As observaçôes sobre a ideia de prazer associada à execução do trabalho criativo e, de forma correspondente e paradoxal, da aceitação de condiçôes precárias de trabalho parecem testemunhar contra as teses de Florida e de outros entusiastas da economia criativa.

O terceiro tema identificado pelos autores trata da questão da distribuição de direitos. Eles observam que as negociaçôes recentes sobre propriedade intelectual na Organização Mundial do Comércio caminham na direção de transferir os direitos de indivíduos para corporações. Aí, a mensagem aos tenentes e entusiastas da economia criativa é um tanto sombria, sobretudo àqueles que consideram que as ideias livres são o sangue da inovação, como é o caso da open innovation: os autores falam de uma "tragedy of the intellectual property rights".

2 Essa ideia tem por referência a tese do célebre biólogo norte-americano Garrett Hardin, que advertia que a superexploração e a ruína seriam o futuro dos recursos (naquele caso, ambientais) de livre acesso. 
O financiamento constitui o quarto tema. Os autores notam que, independentemente da natureza do financiamento (público ou privado), sempre há uma tensão entre o lucro e a arte. Essas tensões são representadas no livro pelos casos do teatro, dos museus e do cinema.

$\mathrm{O}$ quinto tema refere-se à natureza das inovaçôes. Os autores recordam que, nos estudos sobre inovação, as patentes são usadas como proxies ou mesmo como evidências diretas da inovação e que os autores do campo da economia da inovação problematizam esta escolha apontando para os diferenciais de adoção e de mercantilização das inovações. No caso das indústrias criativas, esta relação entre o sucesso de uma inovação e sua difusão é menos clara por causa das interações complexas que levam ao "sucesso" da inovação. Os autores mencionam, por exemplo, a influência da educação e da mídia na modelagem da demanda: esta seria uma das razôes para a prevalência de algumas "escolhas" de bens culturais em mercados em que frequentemente "the winner takes all" (PRATT; JEFFCUTT, 2009, p. 273).

Finalmente, o sexto tema identificado pelos autores tem a ver com a herança institucional e com o "aprisionamento institucional" (institutional lock-in), que explicariam as dificuldades de mudanças nas formas de gestão de companhias de teatro e de museus.

\section{Conclusões}

Neste artigo-resenha foram revisadas contribuições à literatura acadêmica e de cunho político-institucional nas áreas emergentes da economia da cultura e da economia criativa. $\mathrm{O}$ intuito foi identificar suas procedências institucionais, suas contribuições e suas perspectivas analíticas. Também foram evidenciados brevemente alguns elementos do contexto político-econômico no qual emergem essas contribuiçôes. Foram pontuadas questôes cruciais para a compreensão dos rumos do pensamento contemporâneo em Economia, e também em domínios multidisciplinares, com respeito às relações entre criatividade, inovação e cultura, conforme identificadas pela literatura examinada.

As origens das contribuições no âmbito das "políticas culturais-industriais" e grande parte da literatura acadêmica em economia da cultura e em economia criativa encontram-se na Inglaterra, no início dos anos 1980, na forma de iniciativas de governos trabalhistas locais de antigas cidades industriais para fazer frente à escalada de desemprego e insegurança social que se seguiu ao rápido processo de desindustrialização. A partir de 1997, com a ascensão do New Labour de Tony Blair, 
as iniciativas em economia criativa passaram a ser institucionalizadas na esfera federal como estratégia para um desenvolvimento pós-industrial e para o reposicionamento da Grã-Bretanha no cenário de uma nova divisão internacional do trabalho.

Tanto os documentos oficiais do governo britânico como as contribuições acadêmicas em economia da cultura e em economia criativa apresentam classificações muito díspares das atividades ou setores que podem ser qualificados como criativos. Em parte, essa disparidade reflete concepções distintas da própria noção de criatividade - se é associada ao indivíduo ou se diz respeito a aspectos coletivos da partilha de conhecimentos dentro de cadeias complexas de produção. Em parte, a contenda vincula-se a concepçóes distintas sobre o que deve ser objeto das policies, quando o intento deixa de ser estritamente os objetivos tradicionais das políticas culturais e passam a abranger questões como o estímulo a setores industriais, a geração de emprego, renda e de exportaçôes. Essas disparidades conceituais importam especialmente porque os conceitos estão na base das estimativas de crescimento, as quais, por sua vez, fundamentam as propostas de ações fomentadoras dos setores identificados como mais promissores.

Os seis temas elencados por Pratt e Jeffcutt (2009), apresentados ao final da última seção, permanecem essenciais para a compreensão dos rumos deste debate.

São temas de reflexão e de investigação indispensáveis tanto em seu interesse para policies como do ponto de vista essencialmente intelectual. Eles nos levam a indagações fundamentais como: até que ponto essas políticas "culturais-industriais" contribuem para que se atinjam objetivos "culturais", como a preservação do patrimônio histórico, a valorização da diversidade cultural, o acesso a bens culturais e assim por diante? Será que se arriscariam a reduções nos orçamentos da "cultura", conforme tradicionalmente considerada, em favor de aspectos mais "comerciais" das artes e da cultura? Não são questôes ociosas quando se trata de pensar que, no Brasil, o discurso da economia criativa parece ter uma acolhida calorosa tanto nos meios artístico-culturais quanto institucionalmente nas instâncias executivas do governo federal.

Que a emergência dos esforços em termos intelectuais, de política, de mapeamento (ou de proposição) dos setores englobados, de compreensão de suas dinâmicas e de mensuração esteja localizada na Inglaterra, país de industrialização originária e, digamos, de desindustrialização avançada, parece extremamente significativo.

Ao longo das décadas de 1990 e de 2000, as iniciativas de policy se desenvolvem pari-passu com as contribuições intelectuais ou acadêmicas. Essas iniciativas e contribuições parecem pertencer a um Zeitgeist mais amplo desse período, que busca na criatividade, na cultura e na inovação o caminho para novas formas de desenvolvimento. 
Resta ainda notar que os dispêndios públicos federais com os setores criativos perderam força na Inglaterra a partir da volta dos conservadores ao poder nas eleições de 2010. Curiosamente, pelo menos desde a eclosão da crise de 2008, as teses das "indústrias criativas" e das "cidades criativas" parecem ter elas próprias se tornado "produtos de exportação" da Grã-Bretanha, tendo seus scholars se dedicado a seminários e palestras ao redor do globo.

\section{Referências bibliográficas}

AMIN, A. Post-fordism. Oxford: Blackwell, 1994.

BAUMOL, W. J.; BOWEN, W.G. Performing arts: the economic dilemma. Londres: Cambridge, 1996.

BENHAMOU, F. A economia da cultura. Cotia, SP: Ateliê Editorial, 2007.

CAVES, R. Contracts between arts and commerce. The Journal of Economic Perspectives, v. 17, n. 2, p. 73-84, 2003.

. Creative industries: contracts between arts and commerce. New York: Harvard University Press, 2000.

CUNNINGHAM, S. The creative industries after cultural policy: a geneology and some possible preferred futures. International Journal of Cultural Studies, v. 7, n. 1, p. 105-115, 2004.

DCMS - Department of Culture, Media and Sports. A new cultural framework. London: DCMS, 1998.

. Creative industries mapping document. London: DCMS, 2001.

FLEW, T. The creative industry: culture and policy. London: Sage Publ. Ltd., 2012.

FLORIDA, R. Flight of the creative class: the new global competition for talent. New York: Harper Business, 2005.

. The rise of the creative class. And how it's transforming work, leisure and everyday life. New York: Basic Books, 2002.

GARNHAM, N. From cultural to creative industries: an analysis of the implications of creative industries approach to arts and media policy making in the United Kingdom. International Journal of Cultural Policy, v. 11, n. 1, p. 15-29, 2005.

GIRARD, A. Cultural industries: a handicap or a new opportunity for cultural development? Cultural Industries: a challenge for the future of culture. Paris: Unesco, 1982. 
GRABER, C. Snake oil salesmen knew something. Disponível em: <http://www.scientificamerican. com/article.cfm?id=snake-oil-salesmen-knew-something $>$. Acesso em: abr. 2012.

HARDIN, G. The tragedy of the commons. Science, v. 162, n. 3.859, p. 1.243-1.248, 1968. HEALY, K. What's new for culture in the new economy? Journal of Arts Management, Law and Society, v. 32, p. 86-103, 2002.

HESMONDHALGH, D. The cultural industries. London: Sage Publ. Ltd., 2002.

HESMONDHALGH, D.; PRATT, A. C. Cultural industries and cultural policy. International Journal of Cultural Policy, v. 11, n. 1, p. 1-14, 2005.

HMSO - Her Majesty's Stationary Office. Report of the Committee on Financing the BBC. London: HMSO, 1986.

HOWKINS, J. Creative economy: how people make money from ideas. Penguin Global, 2002 [2001].

LANDRY, C. The creative city: a toolkit for urban innovators. New York: Routledge, 2008 [2000]. MARKUSEN, A.; WASSALL, G. H.; DENATALE, D.; COHEN, R. Defining the creative economy: industry and occupational approaches. Economic Development Quarterly, v. 22, n. 1, p. 24-45, 2008.

NESTA - National Endowment for Science, Technology and Arts. Creating growth: how the UK can develop world class creative businesses. London: NESTA Research Report, 2006.

PECK, J. Struggling with the creative class. International Journal of Urban and Regional Research, v. 29, n. 4, p. 740-770, 2005.

PRATT, A. C. Creative cities: the cultural industries and the creative class. LSE Research Online. London: London School of Economics, 2008.

PRATT, A. C.; JEFFCUTT, P. (Orgs.). Creativity, innovation and the cultural economy. Routledge studies in global competition. New York: Routledge, 2009.

THE WORK FOUNDATION Staying ahead: the economic performance of the UK creative and cultural industries. London: The Work Foundation, 2007.

VOLKERLING, M. From cool Britannia to hot nation: creative industries policies in Europe, Canada and New Zealand. International Journal of Cultural Studies, v. 7, p. 437-455, 2001.

ENDEREÇO PARA CORRESPONDENCIA:

Rosana Icassatti Corazza - rosanacorazza@gmail.com

Rua Sapopemba, 522

13.104-170 - Campinas/ SP 
Os trabalhos submetidos à RBI devem enquadrar-se na linha editorial da Revista e observar as normas e orientações indicadas abaixo. Os artigos são avaliados no sistema double-blind review por pelo menos dois pareceristas, ambos de instituições distintas daquela a qual o (s) autor (es) está (ao) vinculado (s). Os direitos autorais dos trabalhos aprovados são automaticamente transferidos à RBI como condição para sua publicação.

1. A RBI publica artigos e resenhas, assim como reedita clássicos e documentos históricos relacionados à temática da Revista. Os artigos devem ser encaminhados via Sistema Eletrônico de Editoração de Revistas (SEER) e as resenhas devem ser encaminhadas por e-mail para o endereço <rbi@ige.unicamp.br>.

2. Podem ser submetidos trabalhos redigidos em português, inglês ou espanhol.

3. Os artigos devem ser submetidos pelo SEER SEM identificação dos autores. Para tanto, é necessário que os autores, no momento da submissão do artigo, preencham suas informações corretamente no sistema.

4. Os trabalhos devem ser digitados no editor de texto Word 6.0 ou posterior; fonte: times new roman; corpo: 12; margens direita, superior e inferior: 2,5cm; margem esquerda: $3 \mathrm{~cm}$; espaçamento entrelinhas: 1,5; e alinhamento justificado. Os artigos não devem ultrapassar 10.000 palavras e as resenhas não devem exceder 2.500 palavras. Tanto os artigos quanto as resenhas devem conter numeração nas páginas.

5. Os artigos devem ser submetidos contendo:

5.1. resumo e título em português ou espanhol e abstract e title em inglês com no máximo 150 palavras;

5.2. até cinco palavras-chave, também em português ou espanhol e em inglês.

5.3. classificação do artigo segundo o Classification System for Journal Articles do Journal of Economic Literature.

6. As citações devem ser abreviadas no corpo do texto e em notas de pé-de-página (autor, ano da publicação e, quando for o caso, página) completas nas referências no final do texto, segundo as normas para apresentação de trabalhos técnico-científicos da ABNT Associação Brasileira de Normas Técnicas. 